\title{
Revesz Syndrome
}

National Cancer Institute

\section{Source}

National Cancer Institute. Revesz Syndrome. NCI Thesaurus. Code C152064.

An autosomal dominant form of dyskeratosis congenita, caused by mutation(s) in the

TINF2 gene, encoding TERF1-interacting nuclear factor 2. It is a fatal disease associated with exudative retinopathy and bone marrow failure. 